\title{
Dengue hemorrhagic fever complicated with acute liver failure: a case report
}

\author{
Chamara Dalugama ${ }^{*}$ and Indika Bandara Gawarammana
}

\begin{abstract}
Background: Dengue is a common arboviral infection with a clinically diverse spectrum of presentations. Although hepatic dysfunction is commonly identified in patients will dengue illness, acute liver failure is rare. The etiopathogenesis of hepatic dysfunction is multifactorial and related to direct viral invasion of hepatocytes, immunological factors and hypoxia particularly in cases of shock in dengue hemorrhagic fever. Ideal management of dengue-related hepatic dysfunction and acute liver failure is still debated.

Case presentation: We report a 53-year-old Sri Lankan Sinhalese male with serologically confirmed dengue fever presenting with evidence of plasma leakage developing acute liver failure evidenced by deranged liver functions, coagulopathy and altered sensorium. In addition to the 'standard care', the patient was managed with intravenous Nacetyl cysteine and blood transfusions even in the absence of bleeding or dropping packed cell volume (PCV), targeting a higher PCV in anticipation of better oxygenation at tissue level. He made a full recovery with no sequential infections.

Conclusion: $\mathrm{N}$-acetyl cysteine and packed cell transfusion aiming at a higher PCV to maintain adequate tissue perfusion during shock may be beneficial in acute liver failure due to dengue virus. Large randomized trials should be carried out to establish the efficacy of these treatment strategies to support these observations and change the current practice.
\end{abstract}

Keywords: Dengue hemorrhagic fever, Liver, Hepatitis, N-acetyl cysteine, Packed cell transfusion

\section{Background}

Dengue fever is an arboviral disease that is endemic in Southeast Asia with four distinct serotypes [1]. Dengue illness has a diverse clinical presentation ranging from asymptomatic subclinical infection to severe multiorgan involvement and death [2]. Dengue illness can present with many unusual manifestations [3-5]. Hepatic dysfunction is a well-reported feature both in dengue fever and in dengue hemorrhagic fever (DHF). Liver involvement in dengue infection can be quite varied, ranging from mild to moderate elevation of serum transaminases to fulminant liver failure [6-13]. Various mechanisms are postulated to explain the hepatic dysfunction seen in dengue illness including direct viral damage, immunological injury and hypoxic injury due to reduced hepatic perfusion during shock [14-21]. Ideal management is still debated. We report an unusual case of an adult with dengue fever leading to acute liver failure and full recovery following treatment. The use of $N$-acetyl cysteine

\footnotetext{
* Correspondence: chamaradalugama@yahoo.com

Department of Medicine, University of Peradeniya, Peradeniya, Sri Lanka
}

(NAC) [22-24], the use of serum lactate levels to monitor improvement and the use of packed cell transfusion to improve tissue-level oxygenation [25-27] are discussed as interesting management strategies.

\section{Case presentation}

We report a 53-year-old Sri Lankan Sinhalese male from Kandy presented to Teaching Hospital, Peradeniya with a history of fever for 4 days. He was previously apparently well and a nonsmoker and a nonethanol consumer. He presented on the fourth day of an acute febrile illness with arthralgia, myalgia, retro-orbital pain and headache. On admission he was having postural dizziness, nausea, vomiting and right upper abdominal pain with severe anorexia. On examination he was oriented in time, place and person, but confused. He was not pale, but a mild tinge of icterus was noted in the sclera. The patient was dehydrated, but the capillary refilling time was less than 2 seconds with warm peripheries. His pulse rate was 96 beats/minute with a supine blood pressure of 120/ $80 \mathrm{mmHg}$. Standing blood pressure was $110 / 90 \mathrm{mmHg}$ with narrowing of pulse pressure. The rest of the 
cardiovascular system was normal. Reduced breath sounds were noted in the right lung base but the rest of the lung fields were normal. He had marked tenderness over the right hypochondrium with a hepatomegaly of $4 \mathrm{~cm}$ below the costal margin. He did not have clinically detectable free fluid in the abdomen.

On admission to the medical unit the patient's complete blood count showed hemoglobin of $12.6 \mathrm{~g} / \mathrm{dl}$, white cell count of $1.85 \times 10^{6}$ cells $/ \mu$ l and platelet count of $36 \times 10^{3}$ cells $/ \mu$ l. His transaminase levels were elevated: aspartate transaminase (AST) was $27,220 \mathrm{U} / \mathrm{L}$ and alanine transaminase (ALT) was 11,100 U/L. Serum bilirubin was $50 \mathrm{mg} / \mathrm{dl}$ with a direct fraction of $45 \%$. The prothrombin time (PT) was 17.1 seconds (control $12 \mathrm{sec}-$ onds) and activated partial thromboplastin time (APTT) was 142.7 seconds (control 29 seconds). Serum albumin was $30 \mathrm{~g} / \mathrm{dl}$ and the corrected calcium value was $1.7 \mathrm{mmol} / \mathrm{L}$ (normal range $2.15-2.57 \mathrm{mmol} / \mathrm{L}$ ). Venous blood gas showed a compensated metabolic acidosis with bicarbonate of $15 \mathrm{mmol} / \mathrm{L}$ and partial pressure of carbon dioxide of $20 \mathrm{mmHg}$. The venous lactate level was $5.8 \mathrm{mmol} / \mathrm{L}$. Renal functions were within the normal range. Serum amylase was $145 \mathrm{U} / \mathrm{L}$ (normal range 1-137 $\mathrm{U} / \mathrm{L}$ ) and serum lipase levels were not available. Urine analysis showed trace protein, and three or four white cells with few granular casts. Bedside ultrasound scan revealed free fluid in perihepatic, subhepatic and pericholycystic spaces with marked gall bladder wall edema and a small right-sided pleural effusion. A diagnosis of DHF complicated with liver involvement was made.

The patient was moved to the high dependency unit and was catheterized. Fluid resuscitation was done initially using crystalloids. He was given a normal saline bolus of $7 \mathrm{ml} / \mathrm{kg}$ due to narrow pulse pressure and fluids were titrated according to blood pressure, urine output and packed cell volume (PCV). The patient was started on a third-generation cephalosporin and an intravenous proton pump inhibitor. He showed mild confusion and altered sleep cycle. In view of deranged liver functions, evidence of coagulopathy and altered sensorium, a possibility of acute liver failure with early encephalopathy was considered. Serum ammonia level measurement was not available at the hospital. The patient was started on oral metronidazole and lactulose. Intravenous vitamin $\mathrm{K}$ $5 \mathrm{mg}$ was given. Blood sugar was checked every 4 hours and corrected. Serum calcium levels were monitored and corrected with intravenous calcium gluconate.

Dengue fever was confirmed by positive nonstructural protein 1 (NS1) antigen and the serotype was identified as DEN 2. Both dengue immunoglobulin $M(\operatorname{IgM})$ and immunoglobulin G (IgG) were positive, suggesting a secondary infection with DENV. Because of severe liver involvement, alternative causes were sought. Tests for viral serologies including hepatitis A IgM, hepatitis B surface antigen and hepatitis C IgM were negative. Leptospira and rickettsial serology was negative and blood cultures were sterile. The patient denied taking a supratherapeutic dose of paracetamol or any other hepatotoxic drugs. He had not taken any ayurvedic or herbal preparations prior to admission as an ailment for fever. Serology for Epstein-Barr virus (EBV) and cytomegalovirus (CMV) was not available in the hospital.

The patient's PCV was maintained around $40 \%$ and he maintained more than $0.5 \mathrm{ml} / \mathrm{kg}$ urine output. Within the next 12 hours, further increase of transaminases was noted (AST 47,220 U/L, ALT 27,688 U/L) and the venous lactate level was raised to $7.8 \mathrm{mmol} / \mathrm{L}$. The patient was started on an intravenous infusion of $N$-acetyl cysteine (NAC) at a rate of $100 \mathrm{mg} /$ hour. The authors decided to transfuse packed cells to increase the PCV in order to improve the oxygen carrying capacity of the blood to relieve possible tissue-level hypoxia and to improve oxygenation at tissue level. The patient was given packed cells at a rate of $100 \mathrm{ml} /$ minute to reach and maintain a PCV of $45 \%$ for 8 hours. Dramatic reduction of the venous lactate level was observed following packed cell transfusion. The patient's postulated time window for plasma leakage (36-48 hours) was over by the following day. Gradual reduction in AST and ALT was noted. The PT and APPT were normalized. On day 5 of admission AST and ALT were less than $200 \mathrm{U} / \mathrm{L}$, and NAC infusion was terminated and the patient discharged. He was in good health with normal liver enzymes, clotting profile and albumin at follow-up visits on day 7 and 2 weeks later.

Table 1 presents the trend of hematological, biochemical, clotting and blood gas parameters during the hospital stay and at follow-up visits.

\section{Discussion}

Dengue is a common mosquito-borne viral disease among humans seen mainly in the Asia-Pacific region [1]. It can present with a diverse clinical spectrum ranging from asymptomatic infection or simple undifferentiated fever to DHF with multiorgan failure. Four distinct dengue viral serotypes (DEN 1-4) are known to cause illness. Infection with one serotype confers protection from reinfection with the same serotype, while reinfection with different serotypes confers no long-term protection and may even predispose the patient to plasma leak and worse clinical outcome [2]. No specific antiviral therapy is available for dengue fever. Close monitoring, detecting patients with plasma leak, meticulous titration of fluids to match the rate of fluid leak in the DHF group and managing complications of fluid leak are the main strategies for management.

Dengue infection can present with various unusual manifestations. Most of these manifestations of dengue 
Table 1 Trend of hematological, biochemical, clotting and blood gas parameters during the hospital stay and at follow-up visits of the patient

\begin{tabular}{|c|c|c|c|c|c|c|c|c|}
\hline Parameter & Day 0 & Day 1 & Day 2 & Day 3 & Day 4 & Day 5 & Day 7 & Day 14 \\
\hline $\mathrm{Hb}(\mathrm{g} / \mathrm{dl})$ & 12.6 & 13 & 14 & 16 & 14.4 & 14.1 & 13.3 & 13.5 \\
\hline WBC $\left(10^{6}\right.$ cells $\left./ \mu l\right)$ & 1.85 & 2.06 & 2.66 & 4.37 & 8.25 & 12.4 & 10.6 & 8.9 \\
\hline Platelets $\left(10^{3}\right.$ cells $\left./ \mu l\right)$ & 36 & 21 & 13 & 9 & 17 & 101 & 334 & 387 \\
\hline AST (U/L) & 27,220 & 47,220 & 27,220 & 12,004 & 1732 & 108 & 88 & 40 \\
\hline $\mathrm{ALT}(\mathrm{U} / \mathrm{L})$ & 11,100 & 27,688 & 11,550 & 4590 & 1001 & 223 & 56 & 28 \\
\hline PT (seconds) & 17.1 & & 17.5 & & 15.5 & & & 12 \\
\hline APTT (seconds) & 142.7 & & & & 56 & & & 25 \\
\hline Creatinine $(\mu \mathrm{mol} / \mathrm{L})$ & 88 & & & & 84 & & & 68 \\
\hline Albumin $(\mathrm{g} / \mathrm{dl})$ & 30 & & 31 & & 35 & & & 42 \\
\hline lonized calcium (mmol/L) & 1.7 & & 1.94 & & 2.05 & & & 2.3 \\
\hline VBG bicarbonate & 15 & 12 & 15.9 & 17 & 20 & & & \\
\hline VBG $\mathrm{PCO}_{2}$ & 20 & 18 & 24 & 26 & 28 & & & \\
\hline VBG lactate & 5.8 & 7.8 & 4.8 & 2.5 & 2.2 & & & \\
\hline Amylase & 145 & & & & & & & \\
\hline
\end{tabular}

$H b$ hemoglobin, $W B C$ white cell count, $A S T$ aspartate transaminase, $A L T$ alanine transaminase, $P T$ prothrombin time, $A P T T$ activated partial thromboplastin time, $V B G$ venous blood gas, $P C O_{2}$ partial pressure of carbon dioxide

fever are underreported, underrecognized or not casually linked to dengue fever, including hepatitis and liver failure [3], myositis [4], encephalitis and other neurological manifestations [5], and so forth.

Hepatic dysfunction is a well-recognized feature in both dengue fever and DHF. Liver involvement in dengue infection could be suspected in patients with dengue fever complaining of abdominal pain, nausea, vomiting and anorexia [6]. Hepatomegaly is present in both dengue fever and DHF but is more common in dengue fever [7]. Clinical jaundice has been detected in $1.7-17 \%$ of patients in various series $[7,8]$. Mild to moderate increase in the transaminases is common in dengue fever and DHF. Souza et al. [9] described elevated transaminases in $74.2 \%$ of patients with serologically confirmed dengue illness $(N$ $=1585$ ) and $3.8 \%$ of them had transaminases at levels similar to acute hepatitis. Interestingly the greatest alterations were observed among females $(p<0.001)$, cases of DHF $(p<0.001)$ and cases with sequential infections $(p=$ $0.001)$. Kuo et a. [10] and Nguyen et al. [11] observed that the level of aspartate aminotrasferase (AST) was higher than that of alanine aminotransferase (ALT). Kuo et al. [10] further observed that transaminases tend to decrease to normal levels within 3 weeks. AST released from damaged striated muscle, cardiac muscle and erythrocytes could explain the higher levels of AST than those of ALT in patients with dengue fever at an earlier stage $[12,13]$. Therefore, a rise in AST might not be a true reflection of hepatic involvement.

The pathogenesis of liver injury in dengue infection is yet to be fully elucidated. Possible hypotheses include direct effects of the virus or host immune response on liver cells, circulatory compromise, metabolic acidosis and/or hypoxia caused by hypotension or localized vascular leakage inside the liver [14].

Studies have shown that dengue virus (DENV) readily infects liver cells in mouse models [15]. High levels of cytokines, particularly interleukin-22 (IL-22) and interleukin-17 (IL-17), were found in mouse models which may responsible for the cytokine-induced liver damage [16]. Sung et al. [17] observed that infiltration of hepatocytes by natural killer cells followed by $\mathrm{T}$ cells was associated with apoptosis of hepatocytes.

Histopathological studies of postmortem specimens of patients who had a fatal outcome have shown that the liver is congested with liver cell necrosis and apoptosis predominantly in midzonal and centrilobular areas, macrovascular steatosis and councilman bodies. Many postmortem reports show little or no inflammation [18, 19]. It is interesting that similar centrilobular necrosis is a typical finding in hypoxic hepatitis [20]. Considering the fact that a severe form of liver necrosis is seen among patients with DHF who present late with prolonged shock, we can postulate the fact that hypoxic injury due to reduced hepatic perfusion is probably an important contributor in causation of liver damage. On the contrary, a few cases of fulminant liver failure have been reported in the absence of shock [3]. Khongphatthanayothin et al. [21] reported an interesting case of liver failure from DENV infection with reversal of portal venous blood flow. They postulate that hepatic sinusoidal obstruction coupled with shock might be the underlying mechanism of liver failure in this disease. 
In our case, the patient presented late during the leaking phase of dengue fever and on admission he had very high liver enzymes with deranged clotting and an elevated lactate level. He was resuscitated with fluids according to the PCV, urine output and hemodynamics. A liver failure regime with oral metronidazole and lactulose was started as he was in early hepatic encephalopathy. Acute liver failure in our case could be explained by initial direct viral damage and indirect immunological injury, and later contributed by splanchnic hypoperfusion due to plasma leak and compensatory redistribution of intravascular fluids and localized vascular leakage inside the liver. We believe the liver is more vulnerable than the kidney in this context because many mechanisms operate in liver injury as already mentioned. Hypoxia and hypoperfusion would have a greater impact on an already virally and immunologically damaged liver than on the kidney.

The patient was started on intravenous $\mathrm{N}$-acetyl cysteine (NAC) infusion. NAC scavenges free radicals, improves antioxidant defense and acts as a vasodilator to improve oxygen delivery and consumption [22]. However, limited data are available in the literature regarding the efficacy of NAC in dengue fever-related liver dysfunction. A retrospective analysis of NAC in dengueassociated liver failure by Kumarasena et al. [23] showed that five patients who survived out of eight were in early (coma grade 1,11) liver failure stage at the time when NAC was started. Habaragamuwa and Dissanayaka [24] reported another case of hepatitis following dengue successfully treated with NAC. Large randomized trials should be carried out to establish NAC efficacy along with appropriate dosage, timing and duration of treatment as there is no consensus on this. The authors decided to continue NAC in the patient until liver enzymes were near normal, anticipating the antioxidant and vasodilator effects might benefit the damaged liver.

During the critical phase of dengue fever the patient's transaminase levels were increasing despite adequate fluid resuscitation with crystalloids. His PCV was around $40 \%$ at the time of admission and he had ultrasonic evidence of fluid leakage.

The authors considered that liver derangement could be partially due to the direct and indirect injury caused by DENV with a significant contribution from the reduced blood and oxygen supply to the liver although the blood pressure and PCV were static. This is possible as the liver is part of the gut and during early shock the hemodynamics are well maintained at the expense of compromised blood to the gut and liver. The circulatory shock, regardless of whether the etiology is cardiac or acute hypovolaemia or plasma leakage as in DHF, causes splanchnic hypoperfusion with no initial change in splanchnic oxygen consumption by diverting blood supply mediated by sympathetic adrenergic stimulation [25], both the liver and the gut are an efficient means of ensuring that vital organs are perfused during acute hypovolaemia [26, 27]. However, this could be counterproductive in a case of damaged liver by direct and indirect effects of DENV leading to further hypoxic damage due to reduced blood supply.

The authors hypothesized that increasing the PCV by transfusing packed cells may increase the oxygen carrying capacity of the blood and help the liver to recover. Based on this hypothesis, during the leaking phase of DHF the index patient was transfused 2 units of blood (1 unit approximates $400 \mathrm{ml}$ of packed cells) at a rate of $100 \mathrm{ml} /$ hour, targeting a PCV of $45 \%$. Over the next 24 hours a reduction of liver enzymes was noted with marked clinical improvement. The venous blood lactated level dropped from a value of $7.8 \mathrm{mmol} / \mathrm{L}$ to $2.2 \mathrm{mmol} / \mathrm{L}$ at the end of $800 \mathrm{ml}$ of blood transfusion over 8 hours. During the next 24 hours the patient's PT and APPT normalized. His liver enzymes were less than $200 \mathrm{U} / \mathrm{L}$ on day 5 and NAC infusion was terminated. At the follow-up visits on day 7 and at 2 weeks the patient did not show any biochemical derangement of liver enzymes, and transaminase levels were in the normal range.

We considered the possibility of maintaining higher central filling pressures with crystalloids to maintain the splanchnic circulation, particularly in low-resource settings where blood products are not available. However, we believe this might worsen plasma leak into the pleural and peritoneal cavities and may be counterproductive. Blood, on the contrary, acts as a colloid, keeps the oncotic pressure within the vasculature and minimizes the plasma leak, and expands the vascular compartment and carries more oxygen.

\section{Conclusion}

Although conclusions cannot be drawn from a single case report, we believe this case will bring light to treating physicians and researchers that increasing packed cell volume by transfusing blood will increase the oxygen carrying capacity and help a virally and immunologically damaged shocked liver to heal without heading toward fulminant liver necrosis and multiorgan failure followed by death. This hypothesis invites a large randomized trial in patients with severe hepatic dysfunction in dengue fever. One group treated with packed cell transfusion to keep the packed cell volume at a higher value compared with a group on 'standard' management where the packed cells are given only in a case of bleeding or dropping PCV with hemodynamic instability will add new knowledge and may change practice. 


\section{Acknowledgements}

Not applicable.

\section{Funding}

Not applicable.

\section{Availability of data and materials}

Data sharing not applicable to this article as no datasets were generated or analyzed during the current study.

\section{Authors' contributions}

CD and IBG examined, assessed and were involved in the management of the patient. Both authors collected and analyzed data. Both authors read and approved the final manuscript.

\section{Ethics approval and consent to participate}

Ethical approval was not obtained for the publication of this case report as this does not involve sharing of the personal details of the patient.

\section{Consent for publication}

Written informed consent was obtained from the patient for publication of this case report. A copy of the written consent is available for review by the Editor-in-Chief of this journal.

\section{Competing interests}

The authors declare that they have no competing interests.

\section{Publisher's Note}

Springer Nature remains neutral with regard to jurisdictional claims in published maps and institutional affiliations.

\section{Received: 23 October 2017 Accepted: 9 November 2017}

Published online: 08 December 2017

\section{References}

1. Halstead SB. Dengue. Curr Opin Infect Dis. 2002;15(5):471-6.

2. Wilder-Smith A, Schwartz E. Dengue in travelers. N Engl J Med. 2005;353: 924-32.

3. Samanta J, Sharma V. Dengue and its effects on liver. World Journal of Clinical Cases: WJCC. 2015;3(2):125-31.

4. Dalugama C, Ralapanawa U, Jayalath T. Dengue myositis and review of literature. Clin Case Rep Res Trials. 2017:2:16-8.

5. Koley TK, Jain S, Sharma H, et al. Dengue encephalitis. J Assoc Physicians India. 2003:51:422-3.

6. Karoli R, Fatima J, Siddiqi Z, Kazmi Kl, Sultania AR. Clinical profile of dengue infection at a teaching hospital in North India. J Infect Dev Ctries. 2012;6: $551-4$.

7. Saha AK, Maitra S, Hazra SC. Spectrum of hepatic dysfunction in 2012 dengue epidemic in Kolkata, West Bengal. Indian J Gastroenterol. 2013;32: 400-3.

8. $\quad$ Trung DT, le Thao TT, Hien TT, Hung NT, Vinh NN, Hien PT, Chinh NT, Simmons C, Wills B. Liver involvement associated with dengue infection in adults in Vietnam. Am J Trop Med Hyg. 2010;83:774-80.

9. Souza LJ, Alves JG, Nogueira RM, Gicovate Neto C, Bastos DA, Siqueira EW, Souto Filho JT, Cezario Tde A, Soares CE, Carneiro RC. Aminotransferase changes and acute hepatitis in patients with dengue fever: analysis of 1,585 cases. Braz J Infect Dis. 2004:8:156-63.

10. Kuo CH, Tai DI, Chang-Chien CS, Lan CK, Chiou SS, Liaw YF. Liver biochemical tests and dengue fever. Am J Trop Med Hyg. 1992;47:265-70.

11. Nguyen TL, Nguyen TH, Tieu NT. The impact of dengue haemorrhagic fever on liver function. Res Virol. 1997;148:273-7.

12. Nath $P$, Agrawal DK, Mehrotra RM. Ultrastructural changes in skeletal muscles in dengue virus-infected mice. J Pathol. 1982;136:301-5.

13. Lee LK, Gan VC, Lee VJ, Tan AS, Leo YS, Lye DC. Clinical relevance and discriminatory value of elevated liver aminotransferase levels for dengue severity. PLoS Negl Trop Dis. 2012;6:e1676.

14. Itha S, Kashyap R, Krishnani N, Saraswat VA, Choudhuri G, Aggarwal R. Profile of liver involvement in dengue virus infection. Natl Med J India. 2005;18:127-30
15. Cabrera-Hernandez A, Thepparit C, Suksanpaisan L, Smith DR. Dengue virus entry into liver (HepG2) cells is independent of hsp90 and hsp70. J Med Virol. 2007;79(4):386-92.

16. Guabiraba R, Besnard AG, Marques RE, Maillet I, Fagundes CT, Conceicao TM, Rust NM, Charreau S, Paris I, Lecron JC. IL-22 modulates IL-17A production and controls inflammation and tissue damage in experimental dengue infection. Eur J Immunol. 2013;43(6):1529-44.

17. Sung JM, Lee CK, Wu-Hsieh BA. Intrahepatic infiltrating NK and CD8 T cells cause liver cell death in different phases of dengue virus infection. PLoS One. 2012;7(9):e46292

18. Martina BE, Koraka P, Osterhaus AD. Denque virus pathogenesis: an integrated view. Clin Microbiol Rev. 2009;22(4):564-81.

19. Aye KS, Charngkaew K, Win N, Wai KZ, Moe K, Punyadee N, Thiemmeca S, Suttitheptumrong A, Sukpanichnant S, Prida M. Pathologic highlights of dengue hemorrhagic fever in 13 autopsy cases from Myanmar. Hum Pathol. 2014;45(6):1221-33.

20. Henrion J. Hypoxic hepatitis. Liver Int. 2012;32(7):1039-52

21. Khongphatthanayothin A, Mahayosnond A, Poovorawan Y. Possible cause of liver failure in patient with dengue shock syndrome. Emerg Infect Dis. 2013: 19(7):1161-3. https://doi.org/10.3201/eid1907.121820.

22. Sklar GE, Subramaniam M. Acetylcysteine treatment for non-acetaminopheninduced acute liver failure. Ann Pharmacother. 2004:38:498-500.

23. Kumarasena RS, Mananjala Senanayake S, Sivaraman K, de Silva AP, Dassanayake AS, Premaratna $\mathrm{R}$, et al. Intravenous $\mathrm{N}$-acetylcysteine in dengue-associated acute liver failure. Hepatol Int. 2010;4:533-4.

24. Habaragamuwa BWP, Dissanayaka P. N-acetylcystein in denque associated severe hepatitis. Indian J Crit Care Med. 2014;18(3):181-2. https://doi.org/10. 4103/0972-5229.128712

25. Chien S. Role of the sympathetic nervous system in hemorrhage. Physiol Rev. 1967;47:214-88.

26. Price HL, Deutsch S, Marshall BE, Stephen GW, Behar MG, Neufeld GR Hemodynamic and metabolic effects of hemorrhage in man, with particular reference to the splanchnic circulation. Circ Res, 1966:18:469-74.

27. Vatner SF. Effects of hemorrhage on regional blood flow distribution in dogs and primates. J Clin Invest. 1974:54:225-35.

\section{Submit your next manuscript to BioMed Central and we will help you at every step:}

- We accept pre-submission inquiries

- Our selector tool helps you to find the most relevant journal

- We provide round the clock customer support

- Convenient online submission

- Thorough peer review

- Inclusion in PubMed and all major indexing services

- Maximum visibility for your research

Submit your manuscript at www.biomedcentral.com/submit
Biomed Central 